\title{
A produção científica sobre mediação da informação em arquivos: uma análise bibliométrica
}

\section{The scientific production about mediation of information in archives: a bibliometric analysis}

\author{
Dayane dos Santos Farias \\ Mestra em Ciência da Informação pela Universidade do Porto \\ Arquivista da Universidade Estadual da Paraíba \\ Thaís Helen do Nascimento Santos \\ Doutora em Informação e Comunicação em Plataformas Digitais pela Universidade do Porto \\ Docente do Departamento de Ciência da Informação da Universidade Federal de Pernambuco
}

\begin{abstract}
Resumo: A mediação da informação tem sido amplamente discutida na Ciência da Informação, sobretudo no ambiente das bibliotecas. Em contrapartida, as reflexões no âmbito dos arquivos carecem de maior aprofundamento. Nesse contexto, este estudo analisa a produção científica sobre mediação da informação em arquivos indexada na base de dados BRAPCI, no período de 2009 a 2019. Objetiva identificar os artigos, autores, vinculação institucional dos mesmos, ano de publicação e autores mais citados. A metodologia utilizada pauta-se na bibliometria, bem como na utilização das técnicas de análise de citação. Os resultados da pesquisa revelam que apesar do crescimento das discussões sobre mediação da informação nos últimos anos, ainda há uma escassez de publicações que abordem a mediação em arquivos de forma mais efetiva, ou seja, há a necessidade de maiores reflexões e aprofundamento sobre a temática em questão.
\end{abstract}

Palavras-chave: Mediação da Informação. Arquivo. Análise bibliométrica. BRAPCI.

\begin{abstract}
The information mediation has been widely discussed in the Information Science, especially in the library environment. On the other hand, the reflections in the scope of the archives need greater study. In this context, this study analyzes the scientific production about mediation of information in archives indexed in the BRAPCI database, in the period from 2009 to 2019. It aims to identify the articles, authors, their institutional binding, year of publication and most cited authors. The methodology used is based on the bibliometric, as well as in the use of citation analysis techniques. The results of the research reveal that despite the growth of discussions on mediation of information in recent years, there is still a scarcity of publications that approaches the mediation in archives more effective, that is, there is a need for greater reflection and deepening about the thematic in question.
\end{abstract}

Keywords: Mediation of information. Archive. Bibliometric analysis. BRAPCI. 


\section{Introdução}

Com a expansão tecnológica e com um cenário em que a busca e o uso da informação têm sido crescentes, as unidades de informação (arquivos, bibliotecas, museus e centros de informação) voltam seus olhares, cada vez mais, para o usuário. Assim sendo, os debates sobre o conceito de mediação entre os pesquisadores da área em Ciência da Informação (CI) têm assumido mais espaço e atenção em salas de aula, congressos e publicações.

Muito tem se discutido acerca da mediação nas unidades de informações (ALMEIDA JÚNIOR, 2009, FARIAS; CERVEIRA, 2019), sobretudo nas bibliotecas. Em contrapartida, percebese a necessidade de maiores reflexões sobre a temática nos arquivos. Brandão e Lima (2016, p. 118) corroboram com esta afirmação quando versam que:

A mediação da informação, bastante presente nos estudos e práticas bibliotecárias, ainda é uma novidade para os arquivistas. Embora na prática tal conceito esteja imbricado nos fazeres profissionais dos arquivistas, pouco se discute sobre a temática nos estudos e pesquisas no campo da Arquivologia.

Santos Neto e Bortolin (2019, p. 10) também assinalam que “[...] o conceito de mediação ainda é discutido de maneira tímida pelos pesquisadores da temática arquivística, o que indica a necessidade de maior atenção e dedicação ao tema [...]”. Diante disso, evidencia-se a incipiência de discussões e pesquisas acerca da referida temática, o que reflete em ações práticas nos arquivos. Salutar destacar que a produção científica contribui para difundir e partilhar conhecimentos sobre determinados temas, fortalecendo e embasando futuras pesquisas. Lousada (2016, p. 128) advoga que "discussões teóricas são fundamentais para o amadurecimento de qualquer área do conhecimento, pois visam suprir lacunas conceituais e metodológicas".

Nesse contexto, o objetivo deste estudo é o de explorar a produção sobre mediação da informação em arquivos por meio da análise bibliométrica. Notadamente, a análise incide nos artigos publicados no período de 2009 a 2019 e indexados na Base de Dados em Ciência da Informação (BRAPCI). Os recortes justificam-se pela apreciação do panorama atual das publicações sobre mediação em arquivos indexada em uma base de dados da área, com ampla visibilidade no cenário brasileiro. 


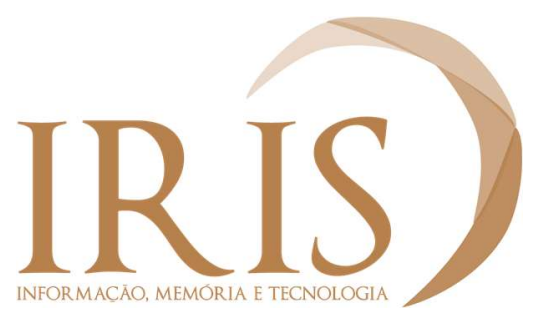

A produção científica sobre mediação da informação em arquivos: uma análise bibliométrica Dayane dos Santos Farias, Thaís Helen do Nascimento Santos

Além desta introdução, o artigo encontra-se estruturado por um capítulo teórico sobre a mediação da informação em arquivos. Apresenta-se, seguidamente, o percurso metodológico adotado, assim como os dados coletados e a sua análise. Por fim, está a conclusão que se ocupa com a apreciação geral dos resultados obtidos e tece sugestões para pesquisas futuras sobre esta temática.

\section{Mediação da informação em arquivos}

A mediação da informação em Ciência da Informação tem sido um tema que ocupa, gradativamente, mais espaço nas discussões em sala de aula, congressos, pesquisas e publicações. O surgimento do termo mediação da informação no Brasil teve como marco o ano de 1995 com um artigo intitulado 'Novas formas de mediação da informação', publicado pela autora Leila Mercadante na revista Transinformação (MERCADANTE, 1995). A autora não apresenta no texto do artigo nenhum conceito de mediação da informação. Trata das novas negociações da informação com a introdução da informática nas bibliotecas e o crescente uso dos meios eletrônicos, enfatizando o que se espera do profissional bibliotecário para adaptar-se a esse novo tempo.

Neste estudo, adotaremos a noção de Almeida Júnior (2009, p. 92) que define mediação como:

[...] toda ação de interferência - realizada pelo profissional da informação -, direta ou indireta; consciente ou inconsciente; singular ou plural; individual ou coletiva; que propicia a apropriação de informação que satisfaça, plena ou parcialmente, uma necessidade informacional.

O mesmo autor caracteriza a mediação em dois tipos: a mediação implícita e a mediação explícita.

A primeira, a mediação implícita, ocorre nos espaços dos equipamentos informacionais em que as ações são desenvolvidas sem a presença física e imediata dos usuários. Nesses espaços, como já observado, estão a seleção, o armazenamento e o processamento da informação. A mediação explícita, por seu lado, ocorre nos espaços em que a presença do usuário é inevitável, é condição sine qua non para sua existência, mesmo que tal presença não seja física, como, por exemplo, nos acessos a distância em que não é solicitada a interferência concreta e presencial do profissional da informação (ALMEIDA JÚNIOR, 2009, p. 92-93). 
A produção científica sobre mediação da informação em arquivos: uma análise bibliométrica

Dayane dos Santos Farias, Thaís Helen do Nascimento Santos

Ao abordarmos esse conceito no contexto informacional, é imprescindível destacarmos os paradigmas da Ciência da Informação, os quais estão diretamente relacionados com o processo de mediação. Ribeiro (2011) apresenta em seus estudos o paradigma custodial e o paradigma póscustodial. O primeiro, também caracterizado como historicista e patrimonialista, enfatiza a ideia de guarda e preservação; possui uma roupagem mais tecnicista, com uma atitude mais passiva em relação ao acesso à informação. Já o segundo, o paradigma pós-custodial, diz respeito à mediação voltada para os interesses dos usuários, menos passiva; onde o acesso à informação é levado em consideração, sendo este o paradigma em consolidação na CI.

No escopo do paradigma pós-custodial, Silva (2009, p. 31) destaca 3 tipos de mediação póscustodial:

- Institucional - que se enquadra dentro das tradicionais instituições culturais, como são as bibliotecas e os arquivos, e é exercida pelos 9 mediadores especializados, como são os bibliotecários e os arquivistas, mas, ao mesmo tempo é partilhada com informáticos e designers de informação, de quem depende a feitura do website através do qual são disponibilizados os acervos em depósito.

- Distribuída e/ou partilhada - ocorre em certos tipos de serviços digitais, como websites e blogs, pertencentes a entidades coletivas e a indivíduos, em que há o(s) mediador(es) que localiza $(\mathrm{m})$, seleciona $(\mathrm{m})$ e disponibiliza $(\mathrm{m})$ conteúdos, há o designer e a empresa que vende ou fornece de forma livre a aplicação e há aderentes ao serviço que são convidados a intervir ativamente com conteúdos e comentários.

- Cumulativa - à mediada que se inovam e expandem mais as possibilidades tecnológicas (novas soluções e produtos) o papel do "prossumidor" (produtor e usuário) cresce enormemente, desenvolvendo um tipo de mediação cumulativa que pode abranger a de designer e de programador, e que produz efeitos e é condicionada através da ativa participação em comunidades que agregam interagentes idênticos ou parecidos.

Perante o cenário da explosão informacional e da mediação pós-custodial, os usuários assumem, efetivamente, o protagonismo nos serviços informacionais. Nos últimos anos, as reflexões sobre o usuário da informação têm como perspectiva a abordagem das práticas informacionais. De acordo com Berti e Araújo (2017), as referidas práticas estão relacionadas com a busca por informação em diferentes contextos, como o social e o cultural. Essa abordagem, no entanto, distingue-se dos já conhecidos estudos de comportamento informacional, pois não se baseia apenas na necessidade do usuário em uma situação específica, mas em diferentes contextos, marcados por interações sociais de forma recíproca. Assim sendo, os estudos de usuários com a abordagem das práticas informacionais 


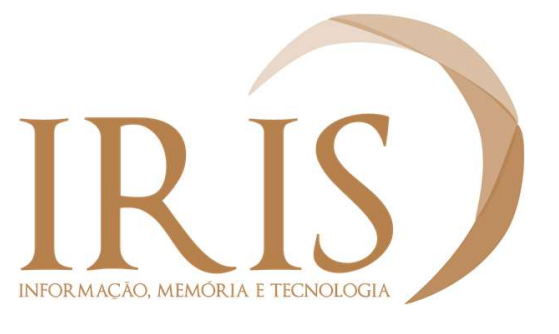

A produção científica sobre mediação da informação em arquivos: uma análise bibliométrica Dayane dos Santos Farias, Thaís Helen do Nascimento Santos

propiciam o desenvolvimento de ações de mediação, buscando identificar as reais necessidades informacionais dos indivíduos.

No que tange à mediação da informação em arquivos, Santos Neto e Bortolin (2016, p. 14) apontam que:

\footnotetext{
a discussão em torno da mediação focada no arquivo, só pode ser realizada a partir do momento que se reconhece o usuário neste ambiente. Sem a presença, física ou virtual, do usuário não faria sentido o arquivo e o acervo nele armazenado. No entanto, a percepção e valorização do usuário nos arquivos é recente e, consequentemente, a discussão em torno da mediação nesses.
}

A mediação arquivística, nas palavras de Lousada (2016, p. 118), “[...] encontra-se presente em diversos momentos das práticas profissionais arquivísticas, desde a produção até a destinação final dos documentos e concretiza-se no momento do acesso do usuário". Sendo assim, considera-se que há um amplo espaço para a exploração e a inserção do tema na área. Partindo desse pressuposto, e de acordo com as práticas e serviços arquivísticos, podemos constatar o quanto a mediação está interligada aos mesmos. Rousseau e Couture (1998) afirmam que as sete funções arquivísticas desenvolvidas no decorrer das atividades do arquivista são: produção, avaliação, aquisição, conservação, classificação, descrição e difusão. A ação mediadora está presente em todos os afazeres do arquivista, implícita e explicitamente.

Ainda em relação às práticas realizadas pelos arquivistas, podemos identificá-las nos dois tipos de mediação abordadas nos estudos de Almeida Júnior (2009). A mediação implícita nos arquivos é caracterizada nas práticas mais técnicas como classificar, organizar, avaliar, descrever e preservar os documentos. Já a mediação explícita, tem a ver com o contato direto com o usuário, que poderá ser também em ambiente digital, tal como ocorre com os serviços de difusão e ação educativa, por exemplo.

O advento tecnológico provocou mudanças no atual cenário informacional e, consequentemente, as ferramentas digitais transformaram o acesso, proporcionando novas formas de realizar a mediação. Desse modo, o arquivista passa a atuar também nesse ambiente, buscando interagir cada vez mais com o usuário, através das ferramentas digitais. Segundo Gama e Ferneda (2010, p. 166), “em vez de se deslocar ao acervo e consultar catálogos impressos o usuário começa a interagir no ambiente Web”. Esse deslocamento do ambiente físico para o digital, pode ser visto como 


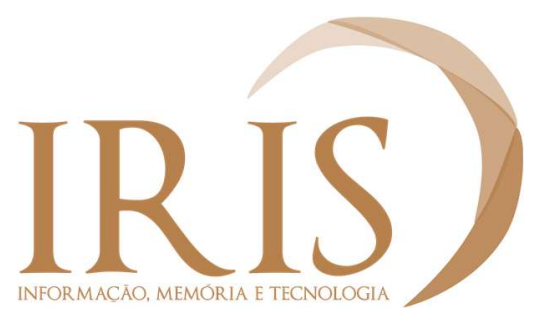

A produção científica sobre mediação da informação em arquivos: uma análise bibliométrica Dayane dos Santos Farias, Thaís Helen do Nascimento Santos

aliado no processo de mediação, de forma a torná-la mais rápida e eficaz, pois contribui para a disseminação e difusão do acervo arquivístico, promovendo, assim, a mediação mais explícita.

Como apresentado, é evidente a mediação nos ambientes de arquivo ao observarmos que a mesma está estreitamente ligada às práticas cotidianas do arquivista. No entanto, as discussões acerca da mediação nessas unidades informacionais ainda são escassas (BRANDÃO; LIMA, 2016, SANTOS NETO; BORTOLIN, 2019). Nesse sentido, é relevante maiores reflexões sobre o tema, para que essas práticas possam ser reconhecidas. “A mediação, seja consciente ou não, está no âmago do fazer do profissional da informação/arquivista e, portanto, precisa ser discutida” (SANTOS NETO; BERTOLIN, 2016, p. 15).

\section{Procedimentos metodológicos}

Neste trabalho foi utilizado o estudo bibliométrico, a fim de verificar a caracterização da produção científica sobre mediação da informação nos arquivos. Utilizou-se também da análise de citação, uma das técnicas utilizadas pela bibliometria.

O Em relação aos estudos bibliométricos, estes:

[...] investigam o comportamento do conhecimento e da literatura, visando basicamente a análise quantitativa do conhecimento registrado, quer sejam: da produção científica dos autores, da produtividade de periódicos sobre determinado assunto, de mensuração e avaliações quantitativas dos processos referentes à utilização de documentos, análise de coautorias, rede de comunicações científicas, análise de avaliação da produção científica, cálculo do fator de impacto, etc... (ALVES, 2009, p. 106).

Seguindo as vertentes mencionadas por Alves (2009), estabelecemos as diretrizes para a organização e a análise dos dados coletados, a saber: título dos artigos, autores (por meio de autoria individual ou coletiva), vinculação institucional destes, ano da publicação, periódico, autores mais citados.

No que tange à análise de citações, as mesmas estimularam os estudos bibliométricos, tendo em vista a relevância em citar autores de trabalhos anteriores. Desse modo, os estudos das análises de citações segundo Vanz e Caregnato (2003, p. 303), “nos permitem mapear um campo emergente ou 


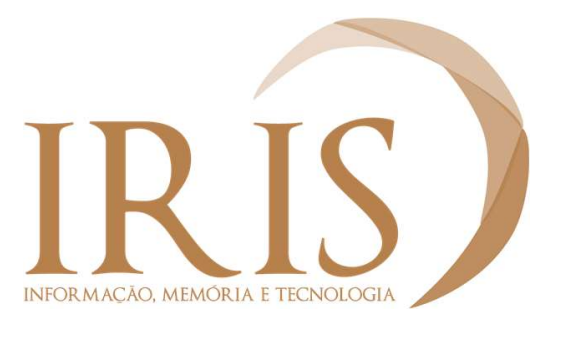

A produção científica sobre mediação da informação em arquivos: uma análise bibliométrica Dayane dos Santos Farias, Thaís Helen do Nascimento Santos

consolidado, identificar seus principais atores e as relações que se estabelecem entre eles e identificar uma série de características do comportamento de uso da informação recuperada".

A coleta dos dados ocorreu na BRAPCI, devido sua representatividade e consistência na área de Ciência da Informação, convergindo, assim, publicações na área da Arquivologia, Biblioteconomia, Museologia e Gestão da Informação. A referida base brasileira disponibiliza trabalhos indexados de periódicos e eventos nas áreas supramencionadas, por meio de recursos de busca simples, com uma interface intuitiva para o pesquisador.

Os artigos foram recuperados com a aplicação dos seguintes termos: 'mediação da informação em arquivos', 'mediação da informação na Arquivologia', 'mediação da informação arquivística' e 'mediação da informação e o arquivista'. Para filtragem dos resultados, os termos deveriam estar presentes no título, nas palavras-chave e/ou nos resumos. A coleta dos dados da presente pesquisa teve início em novembro de 2019 e perdurou até junho de 2020.

Como efeito, foram recuperadas, no total, 50 publicações. Para a verificação da pertinência destas com os termos de busca aplicados, realizou-se a leitura do título, do resumo e das palavraschave. Com esta filtragem, constatou-se que apenas 10 artigos atendiam, efetivamente, o tema em questão.

No que concerne a tabulação dos dados, estes foram organizados em planilhas eletrônicas do Excel em detrimento das diretrizes estabelecidas (mencionadas acima). Contudo, destaca-se que para a análise da variável 'vinculação institucional' também recorremos, em alguns casos, à Plataforma Lattes. A análise de citação, por sua vez, foi realizada manualmente em cada artigo selecionados para amostra. Na segunda etapa da referida análise, o software Excel foi utilizado como apoio para a tabulação, sistematização e estruturação do gráfico.

\section{Análise dos resultados}

Para o processo de coleta de dados foi realizada uma busca no catálogo da BRAPCI, utilizando-se, inicialmente, o descritor 'mediação da informação em arquivos', com o qual foram recuperados o total de 14 trabalhos. Posteriormente, com a análise dos títulos, resumos e palavras-chave, foi identificado que apenas 6 destes 14 artigos estavam atinentes com o tema em estudo. 


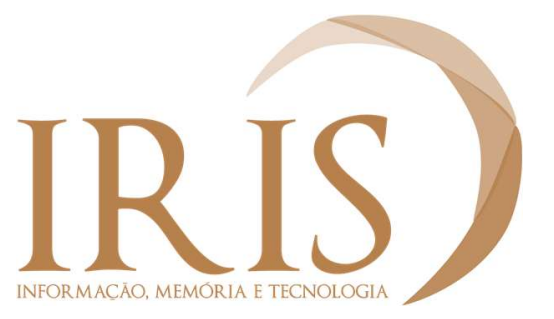

A produção científica sobre mediação da informação em arquivos: uma análise bibliométrica Dayane dos Santos Farias, Thaís Helen do Nascimento Santos

Por meio do termo 'mediação da informação na Arquivologia' foram encontrados 15 resultados, sendo que 2 trabalhos tratavam precisamente da temática. Já com o descritor 'mediação da informação arquivística' foram recuperados 14 trabalhos. Após análise, 6 destes possuíam uma abordagem mais efetiva sobre o tema em questão. O total de trabalhos encontrados, aplicando o termo 'mediação da informação e o arquivista' foram 7; sendo que apenas 4 eram atinentes. Vale ressaltar que na seleção dos artigos recuperados foram excluídos 10 repetidos, isto é, as publicações recuperadas em mais de um termo de busca.

Um ponto a ser destacado no momento da recuperação dos artigos na BRAPCI, foi em relação às palavras-chave. Após análise das mesmas, verificou-se que algumas não representavam o conteúdo da publicação.

Depois da sistematização das publicações recuperadas na BRAPCI, o corpus da pesquisa foi constituído por um total de 10 trabalhos que apresentaram uma abordagem sobre a mediação da informação relacionada aos arquivos. O Quadro 1 apresenta os 10 artigos com os dados referentes ao título, à autoria, o ano de publicação, bem como o periódico em que o trabalho foi publicado.

Quadro 1 - Artigos recuperados na BRAPCI acerca da mediação da informação em arquivos

\begin{tabular}{|c|c|c|c|}
\hline TÍTULO & AUTORIA & $\begin{array}{c}\text { ANO DE } \\
\text { PUBLICAÇÃO }\end{array}$ & PERIÓDICO \\
\hline $\begin{array}{l}\text { A mediação da informação nos } \\
\text { arquivos permanentes: serviços } \\
\text { de referência arquivística no } \\
\text { ambiente digital }\end{array}$ & $\begin{array}{l}\text { GAMA, Fernando Alves; } \\
\text { FERNEDA, Edberto }\end{array}$ & 2010 & $\begin{array}{l}\text { Informação \& } \\
\text { Informação }\end{array}$ \\
\hline $\begin{array}{l}\text { A mediação da informação no } \\
\text { âmbito da arquivística }\end{array}$ & $\begin{array}{l}\text { FERREIRA, Letícia } \\
\text { Elaine; ALMEIDA } \\
\text { JUNIOR, Oswaldo } \\
\text { Francisco }\end{array}$ & 2013 & $\begin{array}{l}\text { Perspectivas em } \\
\text { Ciência da } \\
\text { Informação }\end{array}$ \\
\hline $\begin{array}{l}\text { Mediação da informação em } \\
\text { arquivos: a necessidade da } \\
\text { consolidação da prática do } \\
\text { serviço de referência }\end{array}$ & $\begin{array}{l}\text { SANTA ANNA, Jorge; } \\
\text { CAMPOS, Suelen de } \\
\text { Oliveira }\end{array}$ & 2016 & Biblionline \\
\hline $\begin{array}{l}\text { A mediação da informação e } \\
\text { Arquivologia: aproximações } \\
\text { teóricas }\end{array}$ & LOUSADA, Mariana & 2016 & $\begin{array}{l}\text { Pesquisa Brasileira } \\
\text { em Ciência da } \\
\text { Informação e } \\
\text { Biblioteconomia }\end{array}$ \\
\hline $\begin{array}{l}\text { Mediação da informação } \\
\text { arquivística: o papel do } \\
\text { arquivista pós-custodial }\end{array}$ & $\begin{array}{l}\text { BRANDÃO, Gleise da } \\
\text { Silva; LIMA, Jussara } \\
\text { Borges de }\end{array}$ & 2016 & $\begin{array}{c}\text { Revista Analisando } \\
\text { em Ciência da } \\
\text { Informação }\end{array}$ \\
\hline
\end{tabular}




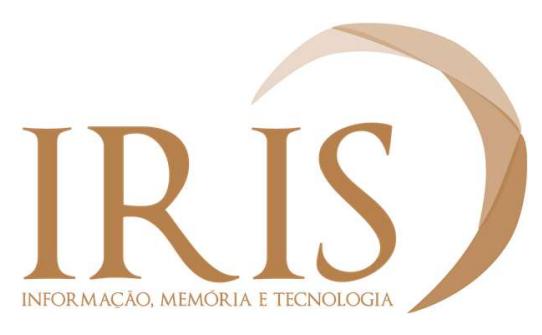

A produção científica sobre mediação da informação em arquivos: uma análise bibliométrica Dayane dos Santos Farias, Thaís Helen do Nascimento Santos

\begin{tabular}{|c|c|c|c|}
\hline $\begin{array}{l}\text { A análise documental de } \\
\text { imagens como processo de } \\
\text { mediação da informação nos } \\
\text { arquivos }\end{array}$ & $\begin{array}{l}\text { SILVA, Sérgio Matias da; } \\
\text { LACERDA, Aline Lopes } \\
\text { de }\end{array}$ & 2018 & Acervo \\
\hline $\begin{array}{l}\text { Papel pedagógico do arquivista } \\
\text { e sua inserção na difusão e } \\
\text { mediação da informação }\end{array}$ & $\begin{array}{l}\text { BALBINO, Giseli Milani } \\
\text { Santiago; CHAGAS, Cíntia } \\
\text { Aparecida }\end{array}$ & 2018 & Ágora \\
\hline $\begin{array}{l}\text { A contribuição das } \\
\text { competências } \\
\text { infocomunicacionais na } \\
\text { atuação do arquivista enquanto } \\
\text { mediador }\end{array}$ & $\begin{array}{l}\text { BRANDÃO, Gleise da } \\
\text { Silva; LIMA, Jussara } \\
\text { Borges de }\end{array}$ & 2018 & Em Questão \\
\hline $\begin{array}{l}\text { Perspectivas de uma literacia } \\
\text { arquivística: reflexões sobre } \\
\text { arquivos, mediação e usuários }\end{array}$ & $\begin{array}{l}\text { VIEIRA, Thiago de } \\
\text { Oliveira; } \\
\text { BITTENCOURT, Paola } \\
\text { Rodrigues; SIQUEIRA, } \\
\text { Marcelo Nogueira de }\end{array}$ & 2019 & $\begin{array}{l}\text { Revista Ibero- } \\
\text { americana de Ciência } \\
\text { da Informação }\end{array}$ \\
\hline $\begin{array}{l}\text { Mediação da informação } \\
\text { através de plataformas digitais: } \\
\text { prática nas bibliotecas arquivos } \\
\text { e museus da área metropolitana } \\
\text { do Porto }\end{array}$ & $\begin{array}{l}\text { FARIAS, Dayane dos } \\
\text { Santos; CERVEIRA, } \\
\text { Maria Elisa. }\end{array}$ & 2019 & Páginas a\&b \\
\hline
\end{tabular}

Fonte: Dados da pesquisa (2020).

O Gráfico 1 apresenta o ano da publicação dos 10 trabalhos encontrados na década de 2009 a 2019 sobre a temática em questão. Podemos verificar que o ano de 2010 foi publicado apenas um trabalho, três anos depois houve mais uma publicação. Em 2016 foram publicados 3 artigos, já em 2018 podemos constatar também um número de 3 artigos publicados. Em 2019 foram publicados 2 artigos. 
Gráfico 1 - Número de publicações em mediação da informação em arquivos no decorrer da última década

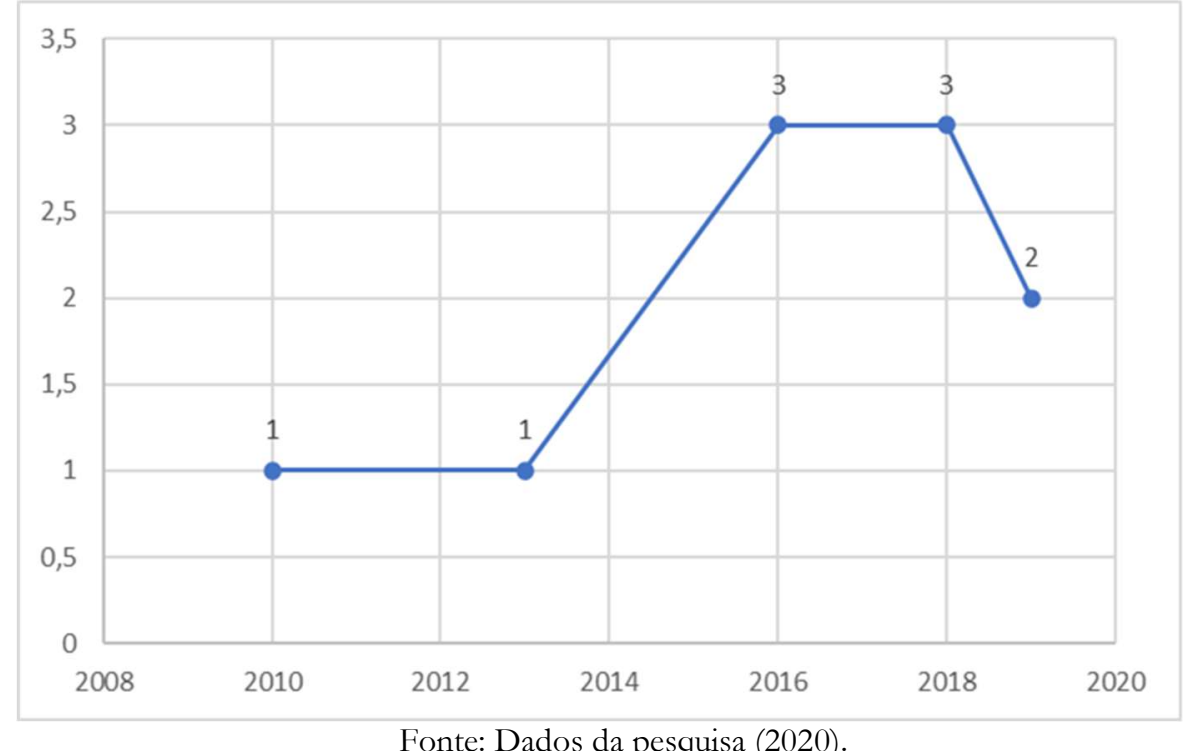

Fonte: Dados da pesquisa (2020).

Através dos dados apresentados no Gráfico 1, podemos perceber que embora haja uma tendência de alta, trata-se ainda de um número pequeno de publicações sobre a temática mediação da informação em arquivos. Uma produção muito escassa diante de uma temática tão relevante, evidenciando, assim, a necessidade de maiores espaços de discussão e reflexão desta no âmbito da Arquivística.

Outro aspecto analisado foi em relação à autoria. Os tipos foram descritos no Gráfico 2.

Gráfico 2 - Autoria individual e coletiva dos artigos analisados

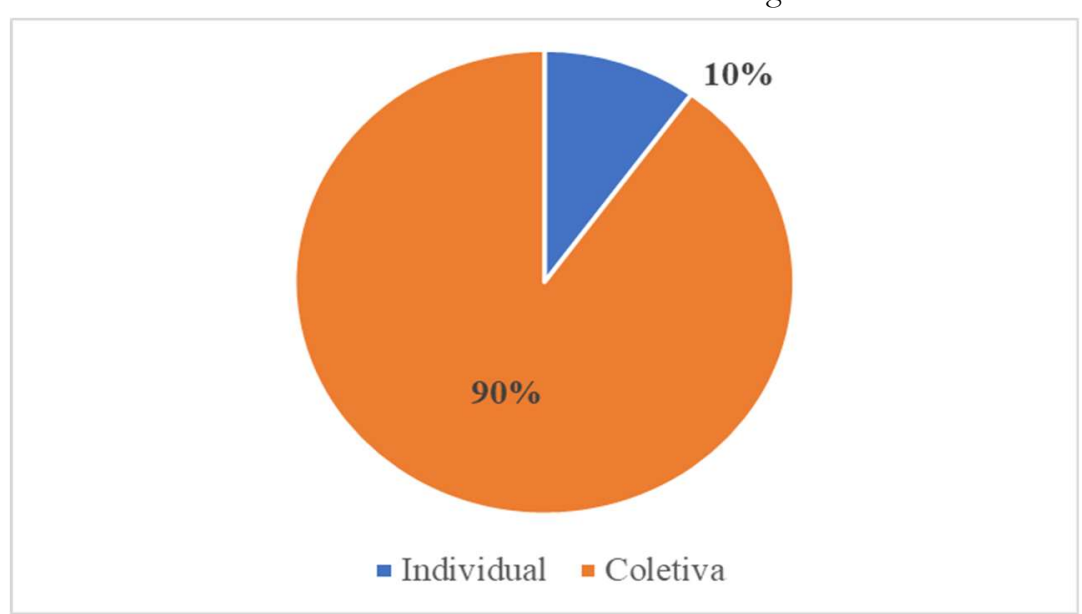

Fonte: Dados da pesquisa (2020). 


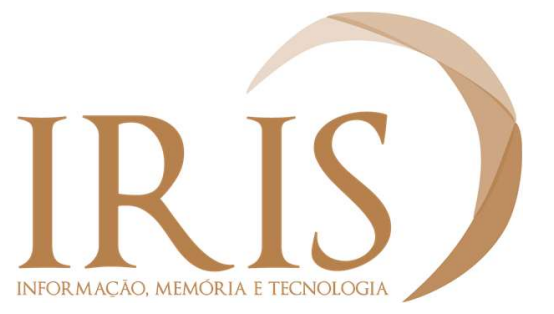

A produção científica sobre mediação da informação em arquivos: uma análise bibliométrica Dayane dos Santos Farias, Thaís Helen do Nascimento Santos

Em relação à produtividade dos autores recuperados nesse estudo, observou-se no Gráfico 2 que 90\% trabalharam em colaboração. Apenas a autora Mariana Lousada produziu individualmente (10\%). Destaca-se as produções de duas autoras, Gleise da Silva Brandão e Jussara Borges de Lima, com dois artigos publicados juntas. Foi encontrado apenas um caso de produção de coautoria de três autores, notadamente por Thiago Oliveira de Vieira, Paola Rodrigues Bittencourt e Marcelo Nogueira de Siqueira.

Considerando a predominância de autoria coletiva na produção dos trabalhos analisados, vale a pena destacar as parcerias dos pesquisadores com seus orientadores de dissertações, tais como o Sérgio Matias da Silva e a Aline Lopes de Lacerda; Dayane dos Santos Farias e Maria Elisa Cerveira, bem como a Gleise da Silva Brandão e a Jussara Borges de Lima.

Quanto aos canais de comunicação, o Quadro 2 descreve os periódicos escolhidos pelos autores para a publicação de seus trabalhos. Observa-se que os artigos encontrados foram publicados em diferentes periódicos da área de CI, sendo um deles internacional (Páginas a \& b, Portugal).

Gráfico 3 - Vinculação institucional dos autores dos artigos analisados

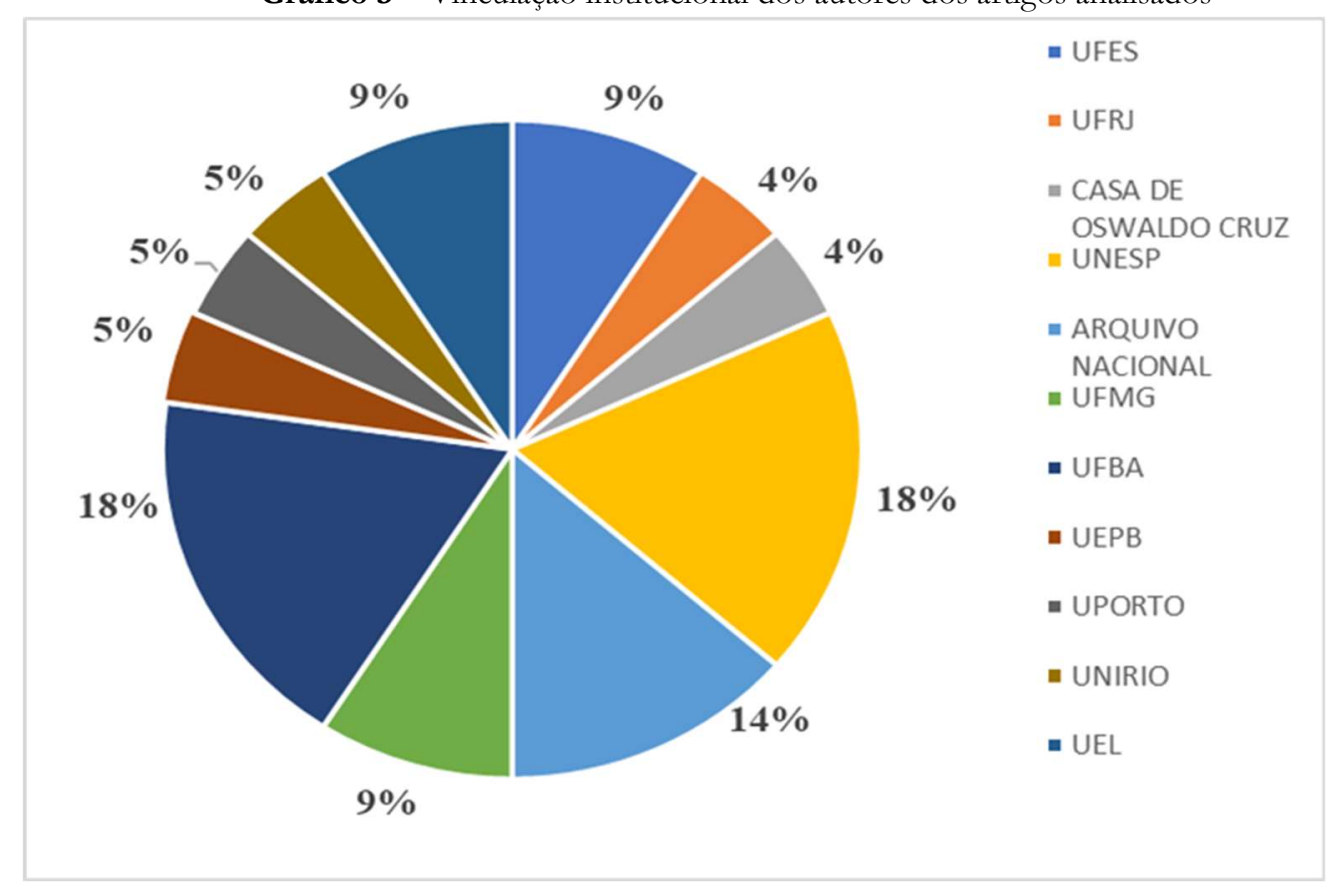

Fonte: Dados da pesquisa (2020). 


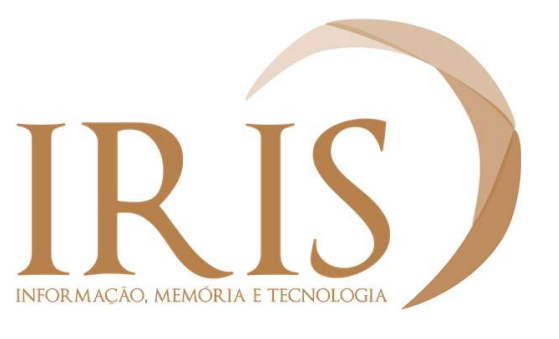

A produção científica sobre mediação da informação em arquivos: uma análise bibliométrica Dayane dos Santos Farias, Thaís Helen do Nascimento Santos

No tocante à vinculação institucional dos autores no período de publicação, conforme descrito no gráfico 3, com 17\%, destacam-se a Universidade Estadual Paulista Júlio de Mesquita Filho (UNESP), a Universidade Federal da Bahia (UFBA) e a Universidade Estadual de Londrina (UEL). A UNESP possui os cursos de graduação em Arquivologia e Biblioteconomia, além do Programa de Pós-Graduação em ciência da Informação, que tem como uma de suas linhas de pesquisa, Gestão, Mediação e Uso da Informação. Já a UFBA possui programa de pós-graduação em CI, além dos cursos de graduação em Arquivologia e Biblioteconomia, os quais compõem o Instituto de Ciência da Informação (ICI). A Universidade Estadual Paulista (UEL), por sua vez, com o curso de Graduação em Biblioteconomia e Arquivologia e também Programa de Pós- graduação em CI assume, de igual modo, posição de destaque nas publicações acerca da mediação da informação em arquivos. Diante dos dados analisados, podemos constatar que é na região sudeste o maior protagonismo nas publicações sobre mediação da informação arquivística.

\begin{tabular}{|c|c|}
\hline \multicolumn{2}{|c|}{ Quadro 2 - Periódicos escolhidos para publicação dos autores } \\
\hline PERIÓDICO & $\mathbf{N}^{\mathbf{o}}$ DE ARTIGO \\
\hline Acervo - Revista do Arquivo Nacional & $\mathbf{1}$ \\
\hline Ágora & $\mathbf{1}$ \\
\hline Biblionline & $\mathbf{1}$ \\
\hline Em Questão & $\mathbf{1}$ \\
\hline Informação \& Informação & $\mathbf{1}$ \\
\hline Páginas a\&b (Portugal) & $\mathbf{1}$ \\
\hline Perspectivas em Ciência da Informação & $\mathbf{1}$ \\
\hline Pesquisa Brasileira em Ciência da Informação e Biblioteconomia & $\mathbf{1}$ \\
\hline Revista Analisando em Ciência da Informação & $\mathbf{1}$ \\
\hline Revista Ibero-americana de Ciência da Informação & $\mathbf{1}$ \\
\hline TOTAL & $\mathbf{1 0}$ \\
\hline
\end{tabular}

Os periódicos encontrados com foco na área de Arquivologia foram os da Revista Ágora, que é editada pelo curso de Arquivologia da Universidade Federal de Santa Catarina (UFSC) e pelo Arquivo Público de Santa Catarina; e a Revista Acervo do Arquivo Nacional, que realiza publicações semestrais desde 1986, divulgando estudos na área da Arquivística.

Conforme a categoria “classificação de Periódicos do Quadriênio 2013-2016”, na área Comunicação e Informação da Plataforma Sucupira, os periódicos analisados possuem os seguintes Qualis CAPES: 


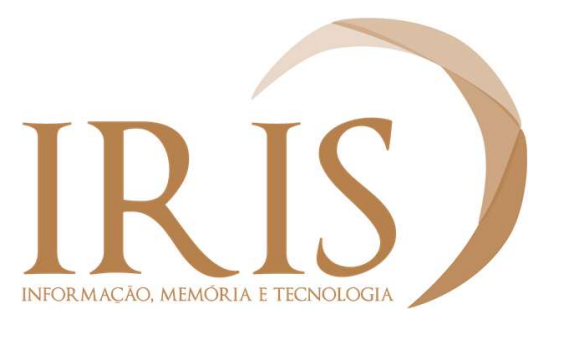

A produção científica sobre mediação da informação em arquivos: uma análise bibliométrica Dayane dos Santos Farias, Thaís Helen do Nascimento Santos

- Qualis A1: Perspectivas em Ciência da Informação;

- Qualis A2: Informação \& Informação, Em questão;

- Quais B1: Revista Ibero-americana de Ciência da Informação, Pesquisa Brasileira em Ciência da Informação e Biblioteconomia, Ágora;

- Qualis B2: Acervo;

- Qualis B4: Páginas a\&b;

- Qualis B5: Biblionline, Revista Analisando em Ciência da Informação.

De acordo com o apresentado no Gráfico 4, podemos verificar os autores mais citados nos trabalhos encontrados; salientando que foram tabulados àqueles citados mais de uma vez.

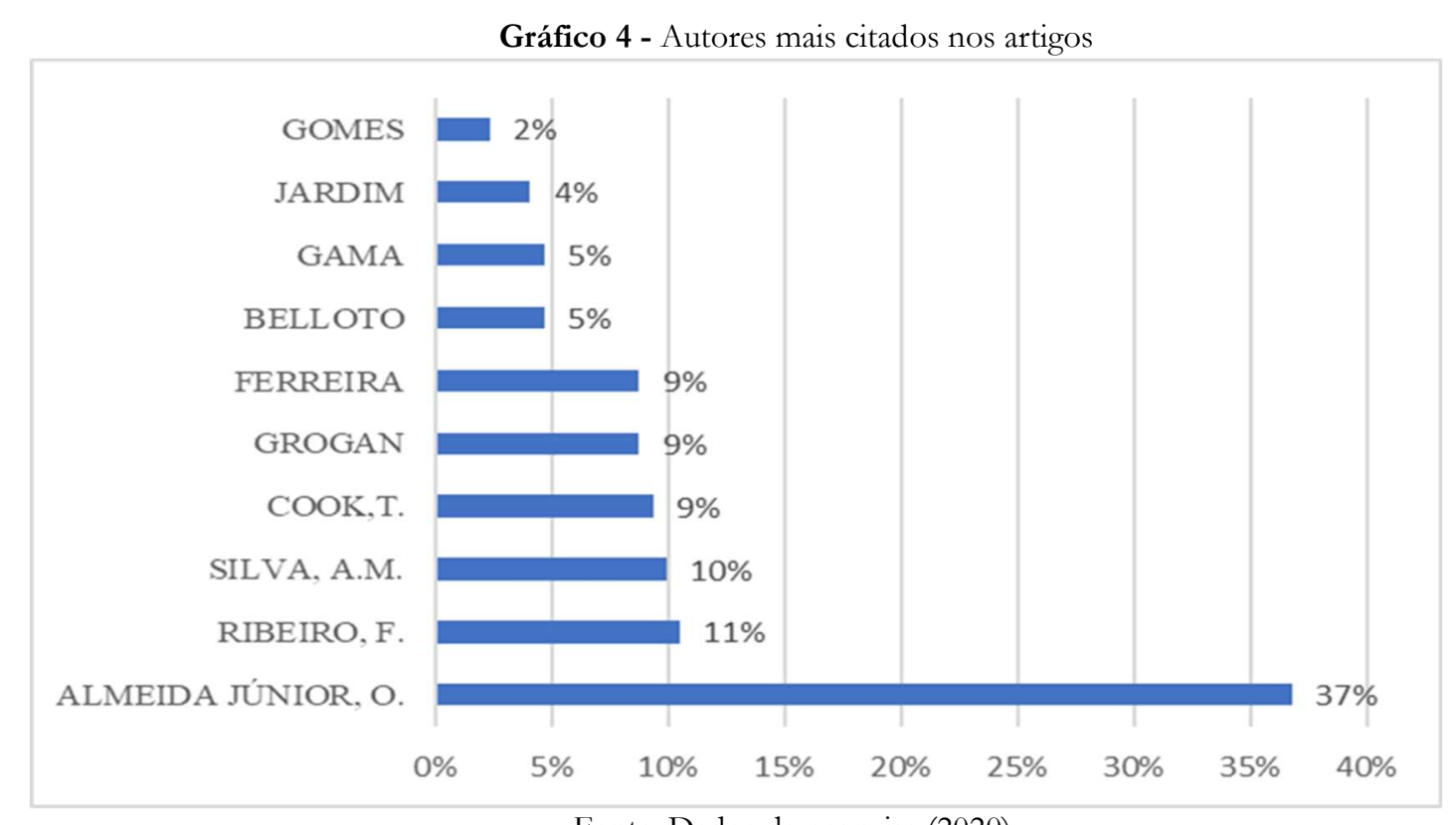

Fonte: Dados da pesquisa (2020).

O autor mais citado, com 63 citações, é o brasileiro Almeida Júnior, docente da Universidade Estadual de Londrina (UEL) e do Programa de Pós-graduação em Ciência da Informação da Universidade Estadual Paulista Júlio de Mesquita Filho (UNESP). O pesquisador atua na temática de mediação da informação, com publicações relevantes na área da Ciência da informação no Brasil.

A segunda mais citada, com o total de 18 citações, é a autora portuguesa Fernanda Ribeiro, professora catedrática do Departamento de Ciências da Comunicação e Informação da Faculdade de 
A produção científica sobre mediação da informação em arquivos: uma análise bibliométrica Dayane dos Santos Farias, Thaís Helen do Nascimento Santos

Letras da Universidade do Porto. A referida autora desenvolve pesquisas relacionadas à recuperação e ao acesso à informação (direcionadas, especialmente aos arquivos), assim como às questões epistemológicas da CI.

Em seguida, com 17 citações, está o autor português Armando Malheiro, professor Catedrático do Departamento de Ciências da Comunicação e da Informação, da Faculdade de Letras da Universidade do Porto. O autor desenvolve trabalhos no domínio da Ciência da Informação e Documentação, Arquivologia, Museologia, Comunicação, Literacia da Informação e Plataformas Digitais.

\section{Considerações finais}

Através das buscas realizadas na base BRAPCI, constatou-se apenas 10 publicações sobre mediação da informação em arquivos ao longo dos últimos 10 anos. Assim sendo, percebemos uma carência na literatura arquivística sobre essa temática.

A análise destas publicações revelou que o autor Almeida Júnior, docente da Universidade Estadual Paulista e da Universidade Estadual de Londrina, é o mais citado nos artigos da área, tendo em vista a sua representatividade nos estudos sobre mediação da informação. Vale destacar que seus estudos fomentam as publicações em Biblioteconomia, Museologia, Gestão da Informação, assim como na Arquivologia. Outrossim, observa-se a predominância da autoria coletiva nos artigos sobre o tema, bem como a maior incidência de publicações advindas das instituições do sudeste do país.

O referido mapeamento busca suscitar outras discussões sobre o tema, ou seja, tem o intuito de provocar reflexões, objetivando viabilizar a realização de futuras pesquisas. Nesse ínterim, é urgente uma abordagem mais ampla, incluindo, por exemplo, a discussão da temática nas disciplinas dos cursos de graduação em Arquivologia, o que irá refletir, como efeito, no maior número de publicações científicas sobre mediação da informação em arquivos. Além disso, evidencia-se a relevância dos estudos bibliométricos para o campo da Arquivologia, servindo de base para outros trabalhos, bem como para o crescimento científico da área. 


\section{IRIS)}

A produção científica sobre mediação da informação em arquivos: uma

análise bibliométrica

Dayane dos Santos Farias, Thaís Helen do Nascimento Santos

\section{Referências}

ALMEIDA JÚNIOR, O. F. Mediação da informação e múltiplas linguagens. Tendências da Pesquisa Brasileira em Ciência da Informação e Biblioteconomia, Brasília, v. 2, n. 1, p. 89-103, jan./ dez. 2009. Disponível em: https://revistas.ancib.org/index.php/tpbci/article/view/170/170. Acesso em: 19 dez. 2020.

ALVES, B. H. Abordagens métricas: análise da produção científica de artigos e rede de colaboração científica dos docentes do Programa de Pós-Graduação em Ciência da Informação, na linha de pesquisa Organização da Informação da UNESP/Marília. Revista de Iniciação Científica da FFC - (Cessada), Marília, v. 9, n. 2, p. 104-115, 9 ago. 2009. Disponível em:

http://www2.marilia.unesp.br/revistas/index.php/ric/article/view/248. Acesso em: 03 ago. 2020.

BALBINO, G. M. S.; CHAGAS, C. A. Papel pedagógico do arquivista e sua inserção na difusão e mediação da informação. Ágora: Arquivologia em debate, Florianópolis, v. 28, n. 57, p. 227-238, out. 2018. Disponível em: https://agora.emnuvens.com.br/ra/article/view/755. Acesso em: 23 jan. 2020.

BERTI, I. C. L. W.; ARAÚJO, C. A. A. Estudos de Usuários e Práticas Informacionais: do que estamos falando? Informação \& Informação, Londrina, v. 22, n. 2, p. 389-401, out. 2017. Disponível em: http://www.uel.br/revistas/uel/index.php/informacao/article/view/31462. Acesso em: 19 dez. 2020.

BRANDÃO, G. D. S.; LIMA, J. B. A contribuição das competências infocomunicacionais na atuação do arquivista enquanto mediador. Em Questão, Porto Alegre, v. 24, n. 3, p. 38, 20 ago. 2018. Disponível em: http://seer.ufrgs.br/EmQuestao/article/view/76752. Acesso em: 20 jun. 2020.

BRANDÃO, G.; LIMA J. B. Mediação da informação arquivística: o papel do arquivista pós-custodial. Revista Analisando em Ciência da Informação, João Pessoa, v. 4, n. especial, p. 118-136, 2016. Disponível em http://racin.arquivologiauepb.com.br/edicoes/v4_nesp/racin_v4_nesp_artigo_01180136.pdf. Acesso em: 16 jan. 2020.

FARIAS, D. S.; CERVEIRA, E. Mediação da informação através de plataformas digitais: prática nas bibliotecas arquivos e museus da área metropolitana do Porto. Páginas a\&b: Arquivos \& Bibliotecas, Porto, n. Especial, p. 15-26, 2019. Disponível em:

https://ojs.letras.up.pt/index.php/paginasaeb/article/view/6279/5908. Acesso em: 12 nov. 2019.

FERREIRA, L. E.; ALMEIDA JÚNIOR, O. F. A mediação da informação no âmbito da arquivística. Perspectivas em Ciência da Informação, Belo Horizonte, v. 18, n. 1, p. 158-167, mar. 2013. Disponível em: http://portaldeperiodicos.eci.ufmg.br/index.php/pci/article/view/1270. Acesso em: 23 jan. 2020.

GAMA, F. A.; FERNEDA, E. A mediação da informação nos arquivos permanentes: serviços de referência arquivística no ambiente digital. Informação \& Informação, Londrina, v. 15, n. 2, p. 148-169, dez. 2010. Disponível em: http://www.uel.br/revistas/uel/index.php/informacao/article/view/7352. Acesso em: 20 set. 2020.

LOUSADA, M. A mediação da informação e Arquivologia: aproximações teóricas. Pesquisa Brasileira em Ciência da Informação e Biblioteconomia, João Pessoa, v. 11, n. 1, p. 117-134, 2016. Disponível em: http://www.periodicos.ufpb.br/ojs/index.php/pbcib/article/view/28204/15247. Acesso em: 15 jan. 2020. 
MERCADANTE, L. M. Z. Novas formas de mediação da informação. Transinformação, Campinas, v. 7, n. 1/2/3, p.33-40, jan./dez., 1995.

RIBEIRO, F. Da mediação passiva à mediação pós-custodial: o papel da Ciência da Informação na sociedade em rede. Informação \& Sociedade: Estudos, João Pessoa, v. 20, n. 1, 2011. Disponível em: http://www.ies.ufpb.br/ojs/index.php/ies/article/download/4440/3420. Acesso em: 04 fev. 2020.

ROUSSEAU, J.; COUTURE, C. Fundamentos da disciplina arquivística. Lisboa: Publicações Dom Quixote, 1998.

SANTA ANNA, J.; CAMPOS, S. O. Mediação da informação em arquivos: a necessidade de consolidação da prática do serviço de referência. Biblionline, João Pessoa, v. 12, n. 2, p. 68-83, 2016. Disponível em: https://periodicos.ufpb.br/ojs2/index.php/biblio/article/view/28257/15516. Acesso em: 19 dez. 2020.

SANTOS NETO, J. A.; BORTOLIN, S. Mediação da informação: afinando o foco na Arquivologia. In: ENCONTRO DA ASSOCIAÇÃO DE EDUCAÇÃO E PESQUISA EM CIÊNCIA DA INFORMAÇÃO DA IBEROAMÉRICA E CARIBE (EDICIC), 10., 2016, Belo Horizonte. Anais [...] Belo Horizonte: UFMG, 2016.

SANTOS NETO, J. A.; BORTOLIN, S. Mediação da informação no campo da Arquivologia. Transinformação, Campinas, v. 31, e180067, 2019. Disponível em: http://www.scielo.br/scielo.php?script=sci_arttext\&pid=S0103-37862019000100508\&lng=en\&nrm=iso. Acesso em: 19 dez. 2020.

SILVA, S. M.; LACERDA, A. L. A análise documental de imagens como processo de mediação da informação nos arquivos. Acervo: Revista do Arquivo Nacional, Rio de Janeiro, v. 31, n. 3, p. 75-87, 2018. Disponível em: http://hdl.handle.net/20.500.11959/brapci/108124. Acesso em: 23 jan. 2020.

SILVA, A. M. da. Mediações e mediadores em Ciência da Informação. Prisma.com. Porto, n. 9, p. 1-37, 2009. Disponível em: https://ojs.letras.up.pt/index.php/prismacom/article/view/2057. Acesso em: 19 dez. 2020.

VIEIRA, T. O.; BITTENCOURT, P. R.; SIQUEIRA, M. N. Perspectivas de uma literacia arquivística: reflexões sobre arquivos, mediação e usuários. Revista Ibero-Americana de Ciência da Informação, Brasília, v. 12, n. 2, p. 385-404, dez. 2019. Disponível em: https://periodicos.unb.br/index.php/RICI/article/view/17159/21346 Acesso em: 14 dez. 2020.

VANZ, S. A. S; CAREGNATO, S. E. Estudos de citação: uma ferramenta para entender a comunicação cientifica. Em Questão, Porto Alegre, v. 9, n. 2, p. 295-307, jul./dez. 2003. Disponível em: https://seer.ufrgs.br/EmQuestao/article/view/75/35. Acesso em: 19 dez. 2020.

Data de submissão: 15 de outubro de 2020

Data de aceitação: 05 de dezembro de 2020 